\title{
Relação docente-discente ém Enfermagem e problemas na formação para o Sistema Único de Saúde*
}

\author{
Nursing faculty-student relationship and issues in the education of nurses for the Brazilian \\ Universal Healthcare System \\ Relación docente-discente en Enfermería y problemas en la formación para el Sistema Único de \\ Salud
}

\author{
Rodrigo Otávio Moretti-Pires ${ }^{1}$, Sônia Maria Villela Bueno ${ }^{2}$
}

\begin{abstract}
RESUMO
Objetivo: Investigar o processo ensino-aprendizado em uma Instituição de Ensino Superior da Região Norte do Brasil, com relação ao modelo pedagógico e a formação do enfermeiro para o Sistema Único de Saúde/ Programa de Saúde da Família (SUS/PSF). Metodos: Grupo focal e entrevistas individuais semi-estruturadas, com seis discentes do último período do curso investigado, analisadas através do marco teórico freireano e literatura do SUS/PSF, por hermenêutica dialética. Resultados: Verticalidade na relação entre docentes e discentes, com falta de autonomia e silenciamento dos alunos, além de falta de articulação entre ensino e a prática do SUS/PSF. Conclusão: Há necessidade de reorientação do ensino em Enfermagem no curso investigado.
\end{abstract}

Descritores: Ensino superior; Enfermagem, Saúde da familia; Educação

\begin{abstract}
Objective: To describe the teaching and learning process of a pedagogical model to educate nurses for the Brazilian universal health care system / family health program (UHS/FHP) in use at a higher education institution in the north of Brazil. Methods: Focus groups and individualized semi-structured interviews with 6 senior nursing students were used to collect the data. The education theory of Paulo Freire and the UHS/FHP literature guided this hermeneutic study. Results: There was a vertical relationship between nursing faculty and students, a lack of autonomy among nursing students, a lack of power for articulation among nursing students, and a lack of articulation of nursing faculty regarding the relationship between the teaching and learning process and the nursing practice in the UHS/FHP. Conclusion: There is a need for re-orientation of the teaching and learning process of nursing at the institution studied.
\end{abstract}

Keywords: Higher education, Nursing, Family health; Education

\section{RESUMEN}

Objetivo: Investigar el proceso enseñanza-aprendizaje en una Institución de Enseñanza Superior de la Región Norte del Brasil, con relación al modelo pedagógico y la formación del enfermero para el Sistema Único de Salud/ Programa de Salud de la Familia (SUS/PSF). Métodos: Se utilizaron Grupo focal y entrevistas individuales semi-estructuradas, con seis discentes del último período de la Institución investigada, cuyos datos fueron analizados a través del marco teórico freireano y literatura del SUS/PSF, por hermenéutica dialéctica. Resultados: Verticalidad en la relación entre docentes y discentes, con falta de autonomía y silenciamiento de los alumnos, además de falta de articulación entre enseñanza y práctica del SUS/PSF. Conclusión: Hay necesidad de reorientación de la enseñanza en Enfermería en la Institución investigada.

Descriptores: Educación superior; Enfermería; Salud de la familia; Educación

\footnotetext{
* Trabalho originado de projeto de pesquisa de uma Universidade Federal da Região Norte do Brasil.

${ }^{1}$ Doutor em Enfermagem Psiquiátrica. Professor do Departamento de Saúde Pública da Universidade Federal de Santa Catarina - UFSC - Florianopolis (SC), Brasil.

${ }^{2}$ Livre-Docente em Enfermagem. Professora Associada do Departamento de Enfermagem Psiquiátrica e Ciência Humanas - EERP da Universidade de São Paulo - USP - São Paulo (SP), Brasil.
} 


\section{INTRODUÇÃO}

A estruturação do sistema de saúde brasileiro foi modulada de forma que o acesso aos serviços de saúde garantidos pelo Estado permeasse as questões de cidadania e a quem caberia ou não este direito. No tocante ao Sistema Único de Saúde (SUS), a garantia legal de acesso a todos os cidadãos - princípio da universalidade - paralelamente a atenção ao usuário fundamentada no princípio da integralidade, desencadeia amplas discussões sobre a necessidade de reformulação do Sistema como um todo ${ }^{(1)}$.

$\mathrm{Na}$ década de 90 do séc. XX, estas questões se tornaram mais contundentes, dado o sucateamento e falta de coerência entre os princípios idealizados para o SUS e sua realidade na atenção à saúde ${ }^{(2)}$, disparando um processo de reformulação na operacionalização do SUS, principalmente com relação à atenção primária. O Ministério da Saúde implementou, então, em 1994 uma nova estratégia: o Programa de Saúde da Família (PSF), que se destina a reorientar o modelo assistencial, tomando a atenção primária como central nas ações do SUS. É defendida a necessidade de remodelamento das práticas dos profissionais de saúde na assistência, sendo preconizado: humanização do atendimento, trabalho em equipe multiprofissional, vínculo entre equipe de saúde e usuários, ação intersetorial, entre outras características deste novo processo de trabalho em saúde ${ }^{(3)}$. No transcurso de uma década da implantação do PSF, diversos avanços foram conseguidos, principalmente no que se refere aos princípios relativos ao acesso ao sistema - universalidade e equidade, conforme fulguram nas diretrizes do SUS. No entanto, a implementação do PSF não se mostrou suficiente no que tange ao preparo do profissional de saúde para a prática cotidiana da atenção e do ato do cuidar consoante com seus princípios ${ }^{(4)}$.

Com relação à Enfermagem, mesmo neste novo modelo, a atuação de grande parte dos enfermeiros permanece obedecendo à lógica do modelo biomédico em saúde, preconizando as ações curativas e a relação profissional-paciente com talhe tradicional, tendo conseqüências diretas no trabalho em equipe e na incoerência entre o PSF idealizado e o PSF de fato. Neste sentido, a literatura científica indica necessidade de investigação do modelo formador dos enfermeiros nas instituições de ensino superior, dados os indícios de que os cursos de enfermagem ainda apresentam um modelo tradicional e desarticulado da formação necessária ao profissional na nova realidade do SUS, e preparado para a atuação no PSF ${ }^{(5-6)}$.

As Diretrizes Curriculares Nacionais (DCN) vigentes para o curso de graduação em enfermagem, consoantes com pedagogia crítica freireana, direcionam a uma formação universitária que enfoque a atenção à saúde integral no contexto histórico-sócio-político-econômico-demográficoepidemiológico, baseada nos problemas da população, preconizando a contextualização, problematização do ensino junto à realidade assim como a resolutividade, para que os futuros enfermeiros vivenciem a prática dos princípios de integralidade, eqüidade e universalidade preconizados pelo SUS já na graduação ${ }^{(6-8)}$. São exíguos os cursos de graduação em enfermagem que tenham bom nível de aderência nesta perspectiva às $\mathrm{DCN}^{(8)}$.

No universo conceitual freireano se defende que a educação é capaz de transformar a realidade, a partir do ser humano nela envolvida e que, principalmente, a postura futura dos alunos remete diretamente ao modelo formador e a relação professor-aluno no processo ensino-aprendizado ${ }^{(9)}$, de forma que, se há desejo de que o enfermeiro se forme para o SUS, de maneira humanizada e buscando a contextualização junto a realidade dos usuários do sistema, é fundamental que a relação docente-discente reflita estes anseios em um novo modelo formativo. Ressalta-se, também, que neste universo conceitual, a historicidade e a postura dos diversos atores envolvidos no processo estão implicadas no que se produz do processo ensino-aprendizagem, de forma que a educação não pode ser tomada como redentora dos problemas da realidade. Longe de encarar a questão de maneira reducionista, Freire preconiza o distanciamento desta perspectiva reducionista e ingênua, para o desenvolvimento de uma visão crítica do processo, assim como a contextualização de fato, pautada nas diversas dimensões e atores implicados no contexto ${ }^{(9)}$.

Haja vista a dicotomia entre como se dá a formação e a ação do enfermeiro preconizada para o trabalho em PSF, assim como a implicação da relação docentediscente, segundo o marco teórico freireano ${ }^{(9)}$, o presente estudo investigou o processo ensino-aprendizado em uma Instituição de Ensino Superior Federal da Região Norte do Brasil, com relação ao modelo pedagógico e a formação do enfermeiro para o SUS/PSF.

\section{MÉTODOS}

Optou-se pela metodologia qualitativa, dada a necessidade de levantar perspectivas sobre a realidade do modelo pedagógico no Curso de Enfermagem investigado, tanto quanto sobre os aspectos relacionados ao ser humano envolvido no processo ${ }^{(10)}$. Foram utilizadas as técnicas de grupo focal ${ }^{(11)}$ e de entrevistas individuais seguindo roteiro semi-estruturado ${ }^{(10)}$, para ampliar a percepção sobre a realidade que emergisse da primeira técnica, trazendo informações tanto de caráter coletivo como individual, respectivamente às técnicas utilizadas. Para o grupo focal, além do moderador, houve um segundo pesquisador no papel de observador. Ao término do grupo focal, que teve a duração de cerca de 
uma hora e meia, ambos se reuniram para discutir os achados e impressões sobre o grupo. As questões norteadoras do grupo focal se referiram à perspectiva sobre o 'outro', ao modelo pedagógico na graduação, à relação professor-aluno, à formação para o SUS e à humanização como temática transversal. Nas entrevistas individuais questionou-se sobre a atuação do profissional no SUS e a questão da humanização, sobre a relação profissional-paciente, também sendo investigados os aspectos do modelo pedagógico em Enfermagem. Todas as discussões e entrevistas individuais foram registradas através de gravação com fita magnética, transcritas posteriormente na íntegra.

Foram critérios de inclusão dos sujeitos: ser discente da universidade federal investigada; cursar Enfermagem; não ter cursado anteriormente ou estar cursando outro curso de graduação; o contato com o SUS e/ou PSF ter se dado exclusivamente no âmbito da graduação, não tendo exercído profissões inseridas na saúde, tais como agente comunitário de saúde ou técnico de enfermagem; estar cursando o último período; cursar todo o curso na mesma turma que os demais sujeitos. O último critério de inclusão é justificado pela necessidade de que todos os integrantes deveriam ter sido submetidos ao mesmo currículo e ao mesmo processo ensino-aprendizado. A inadequação a qualquer um dos critérios acima foi considerada como único critério de exclusão.

Em conformidade com a literatura ${ }^{(11)}$, o grupo focal contou com seis acadêmicos do curso de Enfermagem, dado que dos demais vinte e dois acadêmicos quinze não se enquadravam em um ou mais critérios de inclusão, enquanto os demais não demonstraram interesse em contribuir, apresentando como justificativas falta de tempo ou por não se familiarizarem com a investigação. Com relação às entrevistas individuais, foram convidados os mesmos acadêmicos que integraram o grupo focal.

O modelo utilizado para redução e análise seguiu o processo preconizado pela literatura ${ }^{(10-11)}$, para os materiais oriundos de ambas as técnicas de coleta. As etapas do processo foram: transcrição na íntegra de todos os registros; familiarização do conteúdo através de leitura exaustiva de todo o material; exclusão de todas as considerações dos depoimentos que não se relacionavam aos objetivos da investigação; recorte e organização em categorias por semelhança de conteúdo das considerações, imbuindo-se do marco teórico freireano e da literatura sobre SUS/PSF para esta etapa; identificação de contradições entre as falas assim como em relação a fundamentação teórica que orientou o projeto ${ }^{(10)}$. Na etapa da interpretação o produto final foi confrontado com os pressupostos do universo conceitual freireano ${ }^{(12-15)}$, e também com com a literatura sobre SUS/PSF ${ }^{(1-6)}$, na busca de conteúdos coerentes, dicotômicos ou ímpares, seguindo o preconizado para hermenêutica dialética como talhe de tratamento e análise de informações ${ }^{(10)}$.

O projeto de pesquisa foi conduzido de acordo com as normas que versam sobre pesquisa envolvendo seres humanos no Brasil, e aprovado pelo Comitê de Ética em Pesquisa de uma universidade federal da região Norte do Brasil sob o protocolo n. ${ }^{\circ}$ 230/2006. Os procedimentos para coleta de informação foram iniciados somente após a leitura e explicação do Termo de Consentimento Livre e Esclarecido aos entrevistados, cujo consentimento em participação foi registrado com a assinatura em duas vias do referido termo.

\section{RESULTADOS}

No grupo focal o modelo pedagógico utilizado no curso de enfermagem investigado emergiu com diversas características que retratam um talhe tradicionalista. A primeira característica foi a fragmentação em disciplinas, acrescida de dicotomização de teoria e prática. Os acadêmicos apontaram a necessidade de reorganização do curso, por acreditarem que 'aprender fazendo' é o caminho mais humano, denunciando que no modelo pedagógico do curso a carga teórica é extensa e articulada de maneira incoerente com a prática.

"Pelo nosso Currículo, nós temos a maioria das disciplinas separadas, não integradas. A grande maioria teórica. Só nesse ultimo ano é que nós tivemos Estágio Curricular 1 e 2, nos quais a gente volta para praticar essas matérias. É como se só fosse aula prática depois de ter tido toda a teoria" (Grupo Focal, Integrante 2).

A relação entre professor e aluno foi apresentada como desgastante. Colocam que há ausência de autonomia do aluno durante o processo ensino-aprendizagem, o que promoveria dependência e falta de segurança na prática de enfermagem. A avaliação e a atribuição de notas foram apresentadas como instrumentos silenciadores, uma vez que os alunos que questionavam procedimentos, condutas ou mesmo o método dos professores eram prejudicados em suas avaliações.

"Tem professores nos colocam como seres inferiores a eles, como se a gente não fosse nada e eles sabedores de tudo. Que nunca vamos ser enfermeiras de verdade como eles são" (Grupo Focal, Integrante 1).

"Você não tem autonomia quando está com o professor" (Grupo Focal, Integrante 6).

"Eu nunca disse nada por que professor vai me avaliar, me dar nota”. (Grupo Focal, Integrante 4).

As características apresentadas denunciam existência de verticalidade na relação aluno-professor, ou seja, o professor se coloca como superior ao aluno por possuir um conhecimento teórico pregresso, prejudicando a humanização no processo ensino-aprendizado. Esta 
perspectiva é sobremaneira relevante nos estágios supervisionados, momento em que os acadêmicos deste curso aprendem a ser enfermeiros na prática. De maneira reincidente, a falta de autonomia do aluno no processo também foi apontada.

"Tem professores que ficavam no estágio apenas como supervisor, só olhando o que você está fazendo e depois fica criticando na hora do procedimento, sempre, 'jogando pedra' o tempo todo" (Grupo Focal, Integrante 3)

"É como se fossemos menores. Ele nos trata como alunos e não como futuros enfermeiros" (Grupo Focal, Integrante 1)

As discentes debateram que esta postura do docente de enfermagem é diametralmente oposta às características da profissão como idealizam, dado que para as acadêmicas, a Enfermagem se relaciona essencialmente com uma postura próxima e humanizada no cuidado do outro, configurando-se como um ato de doar-se a este outro, de se colocar no lugar do outro que é um ser humano complexo.

"O men foco é trabalhar com pessoas. Por isso resolvi por Enfermagem e até hoje não me arrependo. Mas meus professores teimam em mostrar que são diferentes disso com a gente". (Grupo Focal, Integrante 2)

As considerações que emergiram no grupo focal foram reafirmadas nas entrevistas individuais. O grande aporte teórico desarticulado com a prática neste curso foi reafirmado.

"Não acho que a universidade ensina tudo. Tudo não. A gente vai aprender no dia-a-dia essa pratica. A faculdade é importante só adquirir as habilidades técnicas" (Entrevistada 1)

Outra informação reincidente foi o corpo docente com características da educação bancária, ou seja, que adota a postura de "depositar" conhecimentos como se os acadêmicos fossem recipientes para os mesmos, destituídos de historicidade e conhecimentos pregressos, que são desconsiderados neste modelo tradicional de ensino. A educação na graduação tem caráter punitivo, sendo cultivada a 'cultura do medo dos professores', refletida na relação verticalizada entre professor e aluno, na ausência de autonomia do discente no processo ensino-aprendizado, a priorização da cultura do silêncio e silenciamento do corpo discente no processo ensino-aprendizagem - termos que se referem ao condicionamento de que o docente tem a última palavra no processo e o discente, por nada saber, deve calar-se ou ser punido.

'Têm muitos professores que você 'tem que agradecer' (tom de sarcasmo) porque te machucaram profundamente. Nossa! Eu aprendi com a professora 'Fulana de tal' que era carrasca. Tem professor que educa para sermos inferiores a ele" (Entrevistada 3)

"Têm professores que tem prazer de reprovar aluno. Ficam caçando 'quero ver neste perído qual aluno eu vou reprovar."(Entrevistada 2)

"Têm professores que eu acho que não estão preocupados se você está aprendendo, mas preferem bumilhar, te botar para baixo. Não vêem o que você estudou e nem o que você sabe, mas o que te falta apenas pela visão deles, é claro!" (Entrevistada 4)

"Na Escola de Enfermagem é assim: o professor é o mestre, é o doutor, entendeu? Tu não passas de um graduando" (Entrevistada 4)

Também emergiu a falta de articulação do ensino com a realidade do processo de trabalho em enfermagem nos serviços de saúde, principalmente no que se refere ao SUS/PSF.

"Me sinto preparada tecnicamente para atuar como enfermeira, mas não sei como vai ser quando eu estiver no serviço de saúde. Principalmente trabalhando na Atenção Básica" (Entrevistada 1)

"Aprender o SUS? Nada. Só sabemos o procedimento de enfermagem. Mas o trabalho em Saúde da Família, como é a relação com equipe (tom sarcástico)... Equipe? Só em teoria. Nem sei ao certo como trabalhar com o médico, dentistas, agentes de saúde. É como se só existissem os enfermeiros, para nossa formação" (Entrevistada 04)

"Tem muito professor que não conhece nada da realidade dos serviços de saúde. Só o hospital é o que interessa pra eles. Mas o hospital nem tem lugar pra todos os enfermeiros, não é? E o posto? Como vamos trabalhar se não aprendemos?" (Entrevistada 5).

A implicação deste modelo na vida profissional futura foi referida nas entrevistas individuais. O professor foi apresentado como arquétipo da futura prática profissional destes acadêmicos, mostrando a importância da horizontalidade entre docente e discente no processo ensino-aprendizado. Além disso, emergiu que no transcorrer do curso destes entrevistados, a maioria dos docentes recorreu ao discurso da humanização como importante para a enfermagem, apesar de que não houve nenhuma atividade pedagógica específica que apontasse para esta direção de aprendizagem.

"As professoras são como um espelho: cada acadêmica tem um pouco de aprendizado com elas, leva consigo e quando for atender um paciente pensa logo nelas" (Entrevistada 1)

"Nós observamos os enfermeiros e a gente vai traçando o nosso perfil. Cada enfermeiro que a gente observa, a gente vai 'pegando' alguma coisinha. Se nosso foco é na saúde pública, então a enfermeira do posto que a gente está agora, por ser muito boa, muito bumana, é a que a gente se espelha (Entrevistada 2)

Em grande medida, estas características permeiam a formação de abordagem tecnicista, focada em disciplinas 
que ensinam a técnica e procedimentos em enfermagem, com ausência de disciplinas que trabalhem especificamente humanização, segundo as depoentes.

"A gente aprende a ser bons técnicos, apesar dos professores sempre dizerem que o enfermeiro é mais que isso. Mas eles só nos cobram e só pedem que sejamos perfeitos técnicos. Outra coisa nem importa na avaliação" (Entrevistada 2)

Em particular, a questão da horizontalidade com o paciente é uma temática essencial para cursos de saúde. Foi definida pelas entrevistadas como "tratar o semelhante como a você mesmo". No entanto, questões pragmáticas tornam-se o foco do profissional na atenção, dificultando o atendimento humanizado e horizontal com o usuário do sistema.

"Falta trabalho especifico sobre a horizontalidade com o paciente na graduação. Na faculdade é ensinado muito da técnica da enfermagem, mas nada em como lidar a técnica na vida do paciente. O paciente é o lugar que você vai aplicar sua técnica, não é visto como um ser humano". (Entrevistada 1)

\section{DISCUSSÃO}

Para o marco teórico freireano ${ }^{(9,13-15)}$, a historicidade dos processos e o protagonismo dos atores sociais para a transformação da sociedade são perspectivas imprescindíveis para o entendimento do contexto, dialetizando as possibilidades entre o historicamente possível e o inédito viável.

Neste sentido, como o modelo pedagógico que emergiu dos discursos - fragmentado em especialidades, com ausência de autonomia do discente e falta de articulação ensino-serviço de saúde - pode formar para o trabalho no SUS/PSF durante os anos de graduação? Ainda mais quando imperam características como a verticalidade na relação docente-discente, falta de exercício de democracia, ausência de trabalho em equipe, e de diálogo com outras profissões de saúde e falta de auto-responsabilidade no processo ensino-aprendizado; quando o modelo de Saúde da Familia se pauta no trabalho em equipe multiprofissional, horizontalidade e vínculo com o usuário e coresponsabilidade com a comunidade.

A dicotomia entre o ensino de enfermagem e a necessidade do SUS, traduzida na inadequação do modelo formador no ensino superior às diretrizes do PSF, não é realidade apenas do curso investigado. A literatura científica apresenta um grande desafio para as instituições formadoras dos recursos humanos em saúde nesta adequação, panorama acentuado frente à necessidade de profissionais de saúde críticos-reflexivos, com habilidades além da técnica. No entanto, as instituições de ensino ainda enfocam suas atividades pedagógicas muito mais na dimensão técnica da formação do que em um talhe ampliado e integrador ${ }^{(15)}$.

Neste sentido, a prática docente cotidiana é distante do que é defendido, tanto nos discursos oficiais como pelos próprios professores universitários, que se esquecem que o ensino de Saúde Coletiva começa no ato de humanizar a relação com o aluno. De maneira paradoxal, esta realidade se dá dentro das universidades que, apesar de serem instituições secularmente destinadas à reflexão, ainda são no Brasil espaços tradicionalistas, havendo urgente necessidade de se abrir o debate para perspectivas amplas e atuais ${ }^{(1)}$. O educando ainda vivencia uma dicotomização, que pode ser incorporada ao profissional que virá a ser, entre o que é ensinado sobre o ser humano na prática profissional e como se dá esta realidade na prática, na medida em que eles próprios não são considerados em sua dimensão humana no contato com os docentes, que esquecem de ouvir seus anseios, problemas, dificuldades e fragilidades durante o processo ensino-aprendizado ${ }^{(16)}$.

Esta dicotomia entre o ensino superior de enfermagem e a orientação oficial do SUS incita ao debate de quais seriam os caminhos para tornar o ensino universitário contextualizado com as políticas públicas de saúde e pautado no desenvolvimento de um comportamento ético-político nos futuros profissionais ${ }^{(17)}$. No âmbito do atendimento no PSF, os profissionais de saúde, muitas vezes, não apresentam formação que os torne capacitados para este entendimento complexo do paciente, desconsiderando as dimensões da dor que não são físicas, subestimando ou supervalorizando a dor e suas manifestações. Cabe ressaltar que a formação orientada para o ensino técnico dos profissionais de saúde atual, é orientada por conceitos antropológicos sobre cultura hegemônicos na década de 1960, em que a cultura do outro - no caso o paciente - é tomada como um saber exótico ou primitivo, com supervalorização do conhecimento biomédico ${ }^{(18)}$.

Este dilema indica para a necessidade da construção de interdisciplinaridade em saúde, não apenas no componente cognitivo próprio da área, mas também nas implicações das dimensões como intersubjetividade, diálogo, respeito ao outro e seus saberes ${ }^{(19)}$. O contexto refere-se, também, à questão de que a base de conhecimento em enfermagem, consolidada a partir dos anos de 1960, é orientada para as ciências biológicas e comportamentais, o que dificulta a formação holística do enfermeiro, o que origina-se na fundamentação epistemológica da formação profissional em enfermagem que, neste contexto, promove formação em que a teoria é dicotomizada com a prática, além de um holismo incompleto $^{(20)}$.

Não bastam disposição e sensibilidade do corpo docente para promover a reorientação do ensino de graduação para os ideais debatidos no presente trabalho, 
apesar da fundamental importância destas características. Paralelamente, existem desafios intrínsecos ao processo de mudança de paradigmas, tais como a estrutura universitária e o mercado, muitas vezes resistentes à mudança de postura do docente ${ }^{(21)}$. Uma outra dimensão da questão refere-se a supervalorização no curso de enfermagem, dos conhecimentos, das habilidades e das técnicas de cunho puramente pragmáticos, abordagem desumanizadora “(...) que reduz a prática educativa ao treinamento técnico-científico dos educandos. Ao treinamento e não à formação"(13). De acordo com os pressupostos freireanos "a necessária formação técnicocientífica dos educandos por que se bate a pedagogia crítica não tem nada que ver com a estreiteza tecnicista e cientificista que caracteriza o mero treinamento"(13). A formação em enfermagem não se distancia desta realidade. "(...) se nos interessa analisar o compromisso do profissional com a sociedade, teremos que reconhecer que ele, antes de ser profissional, é homem"(13).

Tanto quanto qualquer ser humano, os enfermeiros inserem-se em três relações diferentes de comprometimento com colegas profissionais ou pacientes. "Como homem, que não pode estar fora de um contexto histórico-social em cujas inter-relações constroem seu eu, é um ser autenticamente comprometido, falsamente 'comprometido' ou impedido de se comprometer verdadeiramente"(13). Há verticalidade do docente no curso de Enfermagem, caracterizada a predominância de educação bancária, entendida no marco conceitual freireano ${ }^{(12-15,22)}$ por uma relação entre professor e aluno com domínio do primeiro sobre o segundo que deve se submeter gentilmente a autoridade do primeiro, distanciamento do professor do aluno; dicotomia entre teoria ensinada e a realidade na prática. Estas características comprometem, por si só, o lidar horizontal e co-responsável com o usuário do sistema, contribuindo para a manutenção da postura prescritora e dominadora do profissional de saúde em relação ao paciente.

A inexistência de momentos da formação universitária com foco na humanização dos futuros enfermeiros é agudizada pelo fato de que o acadêmico não é abordado respeitosamente pelo docente durante o processo ensinoaprendizado, que desconsidera o primeiro como um ser humano complexo, histórico e social. Estas questões fazem pensar sobre a atuação dos futuros enfermeiros neste mesmo talhe perante o paciente, mesmo dentro do PSF. O modelo de relação humana aprendido durante os

\section{REFERÊNCIAS}

1. Elias PE. Estado e saúde: os desafios do Brasil contemporâneo. São Paulo Perspect. 2004;18(3):41-6.

2. Silva PLB. Serviços de Saúde: o dilema do SUS na nova década. São Paulo Perspect. 2003;17(1):69-85. primeiros "passos" da formação profissional não se refletirá na prática profissional futura? Não é tão somente por documentos oficiais ou pela reformulação do processo de trabalho que se construirão profissionais para o SUS. Regulamentação para a formação com um olhar diferente do tradicional já existe, mas em que medida se torna prática vivida? Deve ser registrada a necessidade de investigações que aprofundem as evidências aqui levantadas e que possibilitem generalizações dos resultados ou que contradigam os mesmos. Outra lacuna é a abordagem dos docentes quanto ao que foi aqui apresentado, dado ser este parte importante do processo ensino-aprendizado e sobremaneira modulador do mesmo.

\section{CONSIDERAÇÕES FINAIS}

Pesquisar em Educação é uma tarefa interessante e rica. Dada a dimensão deste campo de investigação, ainda mais no que tange ao modelo universitário em saúde e suas implicações na atenção, cabe a tarefa de escapar da visão ingênua sobre a Educação como redentora dos problemas, tal como defende Freire. Distanciando-se da visão redentora da educação, ressalta-se que o presente trabalho se refere às relações que se travam no processo de ensino-aprendizagem, limitando-se a este nível de análise, dada a complexidade da temática.

Há exigüidade de estudos que confrontem o modelo assistencial vigente na atenção primária e o significado da defasagem da proposta do Curso de Enfermagem perante as DCN. O presente artigo tentou contribuir para este debate, a partir do lócus universitário, e segundo a perspectiva daqueles para os quais a universidade necessariamente deveria tomar como atores centrais: os universitários. Há que se levantar, dialogar e confrontar sobre os motivos da resistência dos cursos/docentes de enfermagem, e eventualmente dos discentes, como produto da cultura hegemônica, neste contexto entre a formação ansiada e a formação de fato.

A necessidade de reorientação da formação em enfermagem para adequação ao modelo vigente na atenção primária permeia, através de um olhar freireano, o despertar para a necessidade de que a formação acadêmica possa se delimitar como espaço democrático, de forma que os futuros profissionais se deparem com seus pacientes não apenas em nível técnico de excelência, mas também, como seres humanos que cuidam de outros seres humanos, o que é preconizado tanto pelo SUS como pelo PSF.

3. Brasil. Ministério da Saúde. Secretaria de Assistência à Saúde. Saúde da família: uma estratégia para a reorientação do modelo assistencial. Brasília: Ministério da Saúde; 1997.

4. Santos-Filho SB. Perspectivas da avaliação na Política 
Nacional de Humanização em Saúde: aspectos conceituais e metodológicos. Ciênc Saúde Coletiva. 2007;12(4):999-1010.

5. Silva AL, Camillo SO. A educação em enfermagem à luz do paradigma da complexidade. Rev Esc Enferm USP. 2007;41(3):403-10.

6. Pires ROM. O pensamento crítico social de Paulo Freire sobre humanização e o contexto da formação do enfermeiro, do médico e do odontólogo [tese]. Ribeirão Preto: Escola de Enfermagem de Ribeirão Preto da Universidade de São Paulo; 2008.

7. Santana FR, Nakatani AYK, Souza ACS, Esperidião E. Diretrizes curriculares nacionais do curso de graduação em Enfermagem: uma visão dialética. Rev Eletrônica Enferm. 2005;7(3):295-302.

8. Lopes Neto D, Teixeira E, Vale EG, Cunha FS, Xavier IM, Fernandes JD, et al. Um olhar sobre as avaliações de Cursos de Graduação em Enfermagem. Rev Bras Enferm. 2008;61(1):46-53.

9. Freire P. Pedagogia do oprimido. 43a. ed. São Paulo: Paz e Terra; 2005.

10. Minayo MCS. O desafio do conhecimento: pesquisa qualitativa em saúde. 6a. ed. Rio de Janeiro: Hucitec: ABRASCO; 1999.

11. Morgan DL. Focus groups as qualitative research. 2nd ed. Thousand Oaks; London: Sage Publications; c1997.

12. Freire P. Pedagogia da autonomia: saberes necessários à prática educativa. 33a ed. São Paulo: Paz e Terra; 1996.

13. Freire P. Educação como prática da liberdade. $4 a$ ed. Rio de Janeiro: Paz e Terra; 1974.

14. Freire P. Educação e mudança. 28a ed. São Paulo: Paz e Terra;
1979.

15. Freire P. Pedagogia dos sonhos possíveis. 3a ed. São Paulo: Editora UNESP; 2001.

16. Cardozo EE. Repensando a formação do enfermeiro: o processo de conscientização crítica e práticas docentes à luz do referencial ético-humanista. [tese]. Ribeirão Preto: Escola de Enfermagem de Ribeirão Preto da Universidade de São Paulo; 2005.

17. Meira MDD. Avaliação da formação do enfermeiro: percepção de egressos de um curso de graduação em enfermagem [dissertação]. São Paulo: Escola de Enfermagem da Universidade de São Paulo; 2007.

18. Boehs AE, Monticelli M, Wosny AM, Heidemann IBS, Grisotti M. A interface necessária entre a enfermagem, educação em saúde e o conceito de cultura. Texto \& Contexto Enferm. 2007;16(2):307-14.

19. Gattas MLB. Interdisciplinaridade em cursos de graduação na área da saúde da Universidade de Uberaba - UNIUBE [tese]. Ribeirão Preto: Escola de Enfermagem de Ribeirão Preto da Universidade de São Paulo; 2005.

20. Wynne N, Brand S, Smith R. Incomplete holism in preregistration nurse education: the position of the biological sciences. J Adv Nurs. 1997;26(3):470-4.

21. Esperidião E. Holismo só na teoria: a trama dos sentimentos do acadêmico de enfermagem sobre sua formação [dissertação]. Ribeirão Preto:Escola de Enfermagem de Ribeirão Preto da Universidade de São Paulo; 2001.

22. Meira MDD, Kurcgant P. Avaliação da formação de enfermeiros segundo a percepção de egressos. Acta Paul Enferm. 2008;21(4):556-61. 